\title{
Influence of traversing crack on chloride diffusion into concrete
}

\author{
A. Djerbi ${ }^{\text {a }}$, S. Bonnet ${ }^{\text {a }}$, A. Khelidj ${ }^{\text {a,* }}$, V. Baroghel-bouny ${ }^{\text {b,1 }}$ \\ ${ }^{\text {a } G e M(U M R ~ C N R S ~ 6183) ~ I n s t i t u t ~ d e ~ R e c h e r c h e ~ e n ~ G e ́ n i e ~ C i v i l ~ e t ~ M e ́ c a n i q u e ~ I U T ~ d e ~ S a i n t-N a z a i r e, ~} 58$ rue Michel Ange, B.P. 420, \\ F-44606 Saint-Nazaire Cedex, France \\ ${ }^{\mathrm{b}}$ Laboratoire Central des Ponts et Chaussées, 58 Bd Lefebvre, F-75732 Paris Cedex 15, France
}

\begin{abstract}
This study examined the effects of traversing cracks of concrete on chloride diffusion. Three different concretes were tested: one ordinary concrete (OC) and two high performance concretes with two different mix designs (HPC and HPCSF, with silica fume) to show the influence of the water/cement ratio and silica fume addition. Cracks with average widths ranging from 30 to $250 \mu \mathrm{m}$, were induced using a splitting tensile test. Chloride diffusion coefficients of concrete were evaluated using a steady-state migration test. The results showed that the diffusion coefficient of uncracked HPCSF was less than HPC and OC, but the cracking changed the material behavior in terms of chloride diffusion. The diffusion coefficient increased with the increasing crack width, and this trend was present for all three concretes. The diffusion coefficient through the crack $D_{\text {cr }}$ was not dependent of material parameters and becomes constant when the crack width is higher than $\sim 80 \mu \mathrm{m}$, where the value obtained was the diffusion coefficient in free solution.
\end{abstract}

\section{Introduction}

When reinforced concrete structures are built in marine environments, an important deterioration phenomenon that must be taken into account is corrosion of steel reinforcement due to chloride ions. Corrosion of steel reinforcement may decrease its cross-sectional area and deteriorate the bond between the steel reinforcement and concrete, which subsequently leads to degradation of the performance of the reinforced concrete structure. In general, the penetration of species causing deterioration such as chloride ions, oxygen, and water, into concrete is governed by the quality of the cover concrete. Furthermore, when a crack occurs in the cover concrete, the corrosion of the steel reinforcement may be accelerated because the deterioration causing factors can pass through the crack. In recent years the effect of cracking on the penetration of concrete has been the subject of numerous investigations [1-7]. All of these studies have clearly

\footnotetext{
* Corresponding author. Tel.: +332401786 32: fax: +33240178160. E-mail address: abdelhafid.khelidj@univ-nantes.fr (A. Khelidj).

${ }^{1}$ Tel.: +332 401786 17; fax: +33240178160.
}

indicated that the presence of cracks could contribute to an increase in the diffusion coefficient.

Aldea et al. [8] studied the effect of cracking on water and chloride permeability of concrete. Crack widths under loading ranging from 50 to $250 \mu \mathrm{m}$, were obtained using a splitting tensile test. The chloride permeability was evaluated using a rapid chloride permeability test [9] and the water permeability was evaluated by a low pressure water permeability test. The results showed that the chloride permeability increased with the increasing crack width and that the water permeability was significantly more sensitive than the chloride permeability.

Olga et al. [10] examined the effect of crack width and crack wall surface roughness on chloride diffusivity. Crack widths ranging from 80 to $680 \mu \mathrm{m}$ were obtained using a splitting tensile test. The diffusion coefficient was evaluated using a non steady-state diffusion test [11]. The results indicated that chloride diffusion was independent of both crack width and the crack wall roughness.

François et al. [12] studied the effect of crack opening on local diffusion of mortar. Crack openings ranging from 6 to $325 \mu \mathrm{m}$ were obtained using a mechanical expansive core. The 
specimens were exposed to a chloride solution for 15 days and then removed to determine the total chloride concentration perpendicular to crack path. The results showed that the chloride diffusion perpendicular to the crack walls for large cracks (width $\geq 205 \mu \mathrm{m}$ ) was similar to that of the surface. If the cracks that run through the specimens, the studies [5-7] assumed that the diffusion coefficient in the crack in steady-state conditions was equal to the diffusion coefficient in free solution. Therefore, there is no doubt that cracks in concrete greatly affect the durability of reinforced concrete structures. However the characteristics of chloride ion transportation in cracked concrete have not yet been made clear. This paper reports the results of experimental investigations on chloride transportation in traversing cracks of concrete, factors including material composition (ordinary concrete and high performance concretes with two different mixtures). Traversing cracks of designed widths were induced in the concrete specimen using a controlled splitting tensile test. The average crack widths ranged from 30 to $250 \mu \mathrm{m}$. After unloading the chloride diffusion coefficient was evaluated by migration test in steadystate conditions. The diffusion coefficient through the crack was then evaluated by dividing the total chloride diffusion flux of cracked concrete into two flows.

\section{Experimental program}

\subsection{Preparation of the samples}

Three concrete mixes were made: one ordinary concrete (OC) with a w/c of 0.5 and two high performance concretes with two different mix designs, the first had a w/c of 0.32 (HPC), the second had a w/c of 0.38 and contains $6 \%$ of silica fume (HPCSF) (see Table 1). Twenty $110 \times 220 \mathrm{~mm}$ cylindrical samples were prepared from a single batch for each mix. The concrete mixtures were cast in steel molds and compacted using a mechanical vibrator. The cylindrical specimens were stored in a room maintained at $20{ }^{\circ} \mathrm{C}$ and about $95 \%$ relative humidity $(\mathrm{RH})$ for $24 \mathrm{~h}$ after casting, and were cured in water at $20{ }^{\circ} \mathrm{C}$ for 3 months. They were stored in an air-conditioned room $\left(20{ }^{\circ} \mathrm{C}\right.$ and RH $50 \pm 5 \%$ ) until testing. The characteristics of these concretes are shown in Table 2 . The open porosity was measured by water saturation. When the specimens were dried, these were placed in a vacuum container with a $2.5 \mathrm{kPa}$ pressure for $4 \mathrm{~h}$.

Table 1

Details of test series and mix proportion

\begin{tabular}{llcc}
\hline Mix ingredients $(\mathrm{kg} / \mathrm{m} 3)$ & OC & HPC & HPCSF \\
\hline Coarse aggregate, $12.5-20 \mathrm{~mm}$ & 777 & 550 & 579 \\
Medium agrregate, $4-12.5 \mathrm{~mm}$ & 415 & 475 & 465 \\
Sand (Boulonnais), $0-5 \mathrm{~mm}$ & 372 & 407 & 442 \\
Sand (Seine), 0-4 mm & 372 & 401 & 435 \\
Cement CPA-CEM I 52.5 & 353 & 461 & 360 \\
Silica fume & - & 0 & 22 \\
SP (e.s.) & - & 12.4 & 12 \\
Retarder (e.s.) & - & 3.3 & 2.5 \\
Total water & 172 & 146 & 136 \\
$w / c$ & 0.49 & 0.32 & 0.38 \\
$w /(C+$ SF $)$ & 0.49 & 0.32 & 0.36 \\
\hline
\end{tabular}

Table 2

Material properties measured at 28 days and diffusion coefficient

\begin{tabular}{llll}
\hline & OC & HPC & HPCSF \\
\hline Module of elasticity $(\mathrm{GPa})$ & 22 & 31 & 36 \\
Compressive strength $(\mathrm{MPa})$ & 46 & 75 & 85.5 \\
Dry apparent density $\left(\mathrm{g} / \mathrm{cm}^{3}\right)$ & 2.35 & 2.55 & 2.46 \\
Open porosity measured by & 12.1 & 11.4 & 10 \\
$\quad$ water saturation $(\%)$ & $1.810^{-12}$ & $0.7610^{-12}$ & $0.2610^{-12}$ \\
Diffusion coefficient $\left(\mathrm{m}^{2} / \mathrm{s}\right)$ & & & \\
\hline
\end{tabular}

Then, with the vacuum pump still running, the container was filled with water saturated with $\mathrm{NaOH}(0.025 \mathrm{~mol} / \mathrm{l})$ and $\mathrm{KOH}$ $(0.083 \mathrm{~mol} / \mathrm{l})$ in order to immerse the specimen. The vacuum was maintained for $24 \mathrm{~h}$ before allowing the air to enter into the container [13]. Concrete cylinders were cut using a diamond blade saw to obtain $50 \mathrm{~mm}$-thick discs. Three were extracted from each cylinder for splitting tensile test. After cutting, the lateral surface of discs was sealed with two epoxy resin coats in order to ensure one-dimensional chloride flow through the discs.

\subsection{Precracking of samples using controlled splitting test}

Controlled splitting tests were used to induce cracks in the specimens. Diametrical loading (i.e. under Brazilian test configuration), is one of the methods for estimating the tensile stress of concrete through indirect tension. This stress mode was applied to the discs (110 $\mathrm{mm}$ in diameter and $50 \mathrm{~mm}$ in thickness). These discs can be diametrically loaded until obtaining a predetermined lateral displacement (see Fig. 1a). Two LVDT sensors, with a range of $500 \mu \mathrm{m}$ and a precision of $1 \mu \mathrm{m}$, were used to measure the lateral displacement which is normal to the load axis along the two opposite faces of the disc. Their average was called lateral displacement or crack opening displacement (COD) [14]. The sensors (LVDT) were maintained by two Ubolts clamped to the disc via screw-punch (see Fig. 1). Each disc was subjected to 4-10 cycles, in order to obtain various lateral displacements under loading. The desired maximum displacement COD under loading was obtained during the measurement by considering as a reference the previous displacement COD which was recorded $30 \mathrm{~min}$ after unloading. This new reference allowed the measurement of crack opening of more than $500 \mu \mathrm{m}$. Imposed crack openings under loading were 200, 300, 400, 500, 600 and $700 \mu \mathrm{m}$. The loading induced tensile stresses concentrated around the diametrical section perpendicular to the loading plane. The damage was localized and a single crack crossing the disc was generally observed in this plane.

\subsection{Steady-state migration test}

Since diffusion experiments are time-consuming, steadystate migration tests were developed to accelerate chloride ions through the concrete [15-17]. Each specimen was placed between the two compartments of a cell where flat silicone circular seals ensure that the system is leaktight (Fig. 2). The solutions were made with $\mathrm{NaCl}(0.513 \mathrm{~mol} / \mathrm{l}), \mathrm{NaOH}$ $(0.025 \mathrm{~mol} / \mathrm{l})$ and $\mathrm{KOH}(0.083 \mathrm{~mol} / \mathrm{l})$ in the upstream compartment, and $\mathrm{NaOH}(0.025 \mathrm{~mol} / \mathrm{l})$ and $\mathrm{KOH}(0.083 \mathrm{~mol} / \mathrm{l})$ in the 


\section{a. Schematic representation of COD measurement set-up}

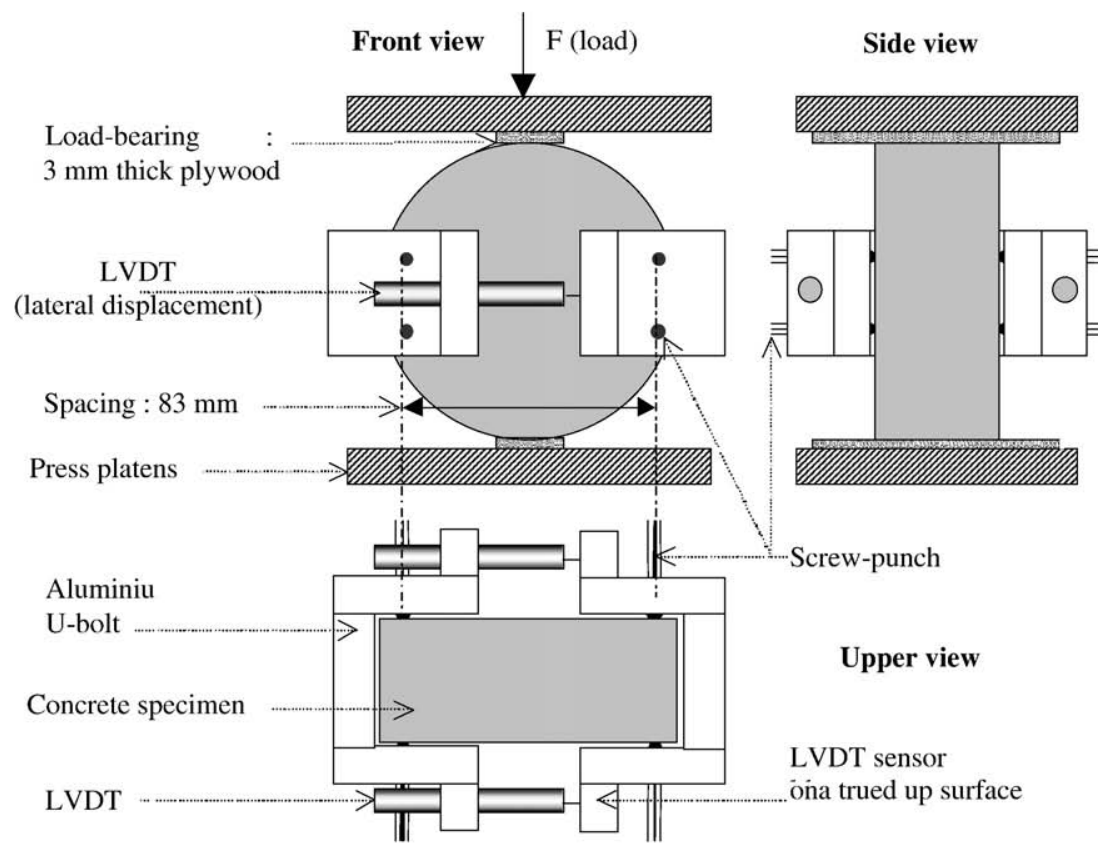

b. Photography of specimen during the test

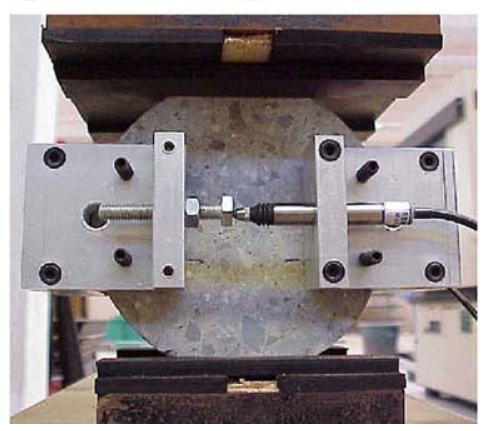

Fig. 1. Controlled splitting test.

downstream compartment. A $12 \mathrm{~V}$ potential difference was applied between the sides of the concrete sample and the test was carried out at temperature $T=20 \pm 5^{\circ} \mathrm{C}$. The downstream solution was sampled, and samples were titrated with silver nitrate

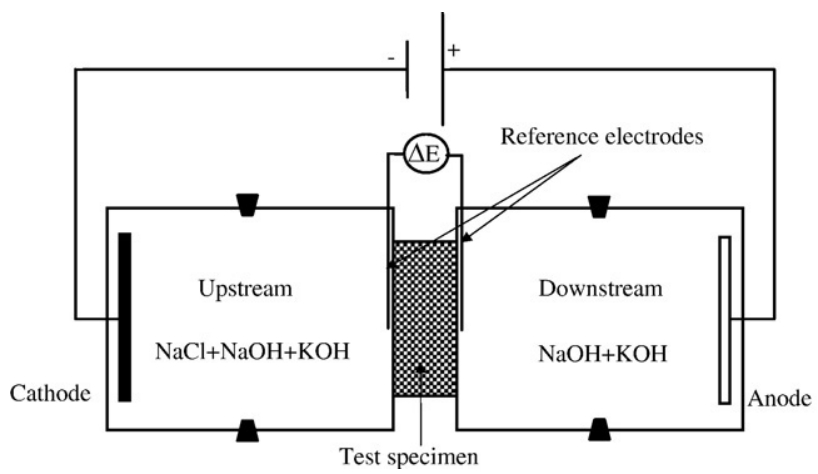

Fig. 2. Migration cell.
$(0.05 \mathrm{M})$. As the flux became constant, the Nernst-Planck relation allowed us to determine the value of the diffusion coefficient, as in Eq. (1):

$J(x)=-D_{\mathrm{e}} \frac{\partial c}{\partial x}+D_{\mathrm{e}} \frac{z F E}{R T L} c+c v(x)$

where $D_{\mathrm{e}}$ is the diffusion coefficient of concrete $\left(\mathrm{m}^{2} / \mathrm{s}\right), c$ is the chloride concentration of the upstream compartment $\left(\mathrm{mol} / \mathrm{m}^{3}\right)$ assumed to be constant, $J(x)$ is the flux of chloride ions (mol/ $\left.\left(\mathrm{m}^{2} \mathrm{~s}\right)\right), z$ is the chloride ion valency $(z=1), F$ is the Faraday constant $(F=96480 \mathrm{~J} /(\mathrm{V} \mathrm{mol})), E$ is the actual potential drop between the surfaces of specimen $(V), R$ is the gas constant $(R=8.3144 \mathrm{~J} /(\mathrm{mol} \mathrm{K})), T$ is the absolute temperature $(K), L$ is the sample thickness $(m)$ and $v(x)$ is the velocity of the solute $(\mathrm{m} / \mathrm{s})$.

If the concrete is saturated, the velocity of the solute can be neglected. Since the potential drop is $\geq 10 \mathrm{~V}$, ions migrate as primarily as a result of the electrical field rather than of the 
concentration gradient. This ensures that the diffusion flow can be neglected in the experiments [15]. Eq. (1) can be simplified and then Eq. (2) is obtained:

$D_{\mathrm{e}}=\frac{L}{c} \frac{R T}{z F E} J$

To establish a steady state, the concentration gradient must be constant during the test. Therefore we had to renew the upstream and downstream solutions frequently.

The evolution of current during testing showed a small increase at the beginning of the test and then a stabilisation for all concretes. For the most cracked concrete, production of chlorine gas was observed at the anode, which was also observed by [5].

\section{Results and discussion}

\subsection{Effect of splitting tensile stress}

This test was carried on six discs of each concrete. These discs were subjected to $4-10$ cycles until various lateral displacements under loading of 200, 300, 400, 500, 600 and $700 \mu \mathrm{m}$ were obtained. After unloading the average crack width on both faces of the discs was obtained through measurements of the crack width at ten points using a videomicroscope with 200 times magnification.

Fig. 3 presents the material effect on recovery of the crack width after unloading. Results indicate that all the materials tested exhibited comparable trends for the entire range of crack widths. The mean crack width for OC seems slightly higher than for HPC and HPCSF. A similar result was found by Aldea [8]. This might be explained by the morphology of the cracks (observed by microscopy): OC exhibits a more tortuous crack than HPC and HPCSF. In OC the cracks penetrates the matrix and the interface transition zone of the aggregates, and microcracking of the matrix is also probable, thus resulting in a less elastic material behavior. For HPC and HPCSF the crack penetrate through the aggregates and the matrix. The two HPC mix designs that were tested showed similar behavior in terms of crack recovery.

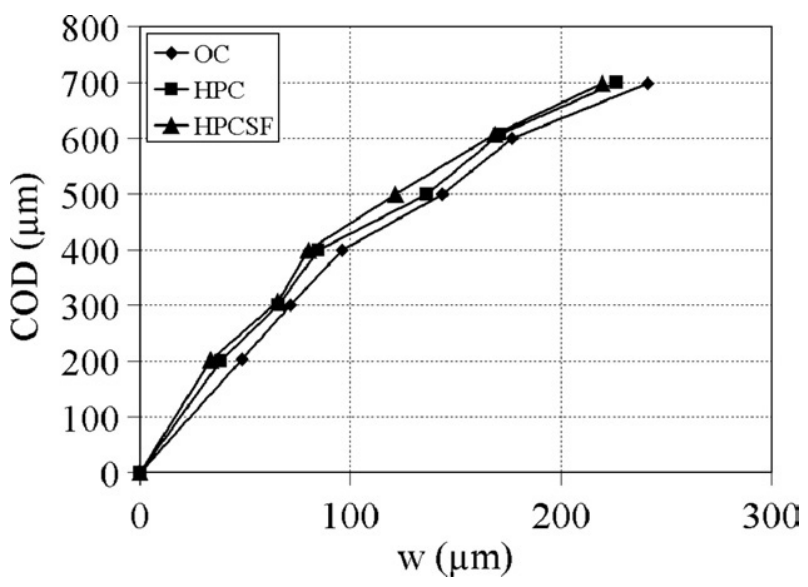

Fig. 3. Crack width versus crack opening displacement under loading.

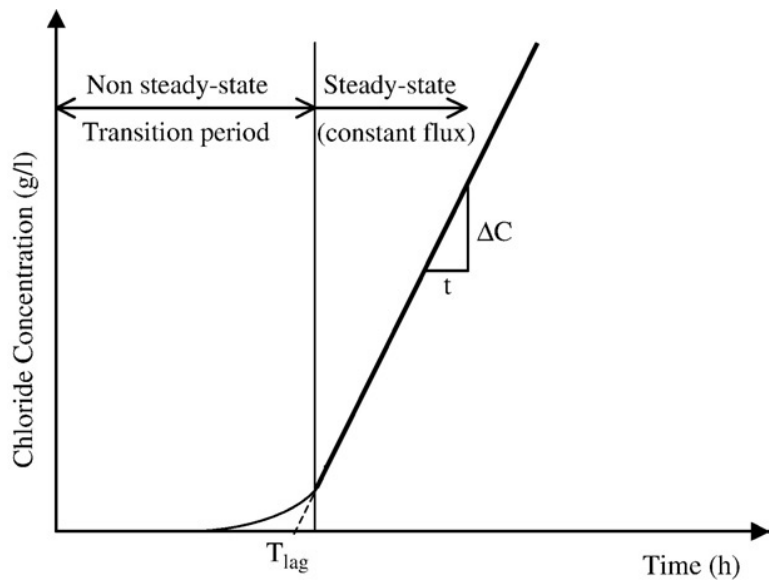

Fig. 4. Schematic representation of non steady-state and steady-state conditions of chloride migration.

\subsection{Influence of cracking on the steady-state migration test}

Fig. 4 is a schematic representation of the total increase of chloride concentration in the anode solution, with elapsed time. Two distinct phases with respect to the change of chloride concentration are acknowledged. The first is a phase where chloride ions are in the process of migrating through saturated pores in concrete and hence have not yet reached the anode compartment. This phase is normally called a transition period and the migration of chloride ions is under non steady-state conditions. The second phase is called the steady-state period where the increase of chloride concentration becomes constant with elapsed time, providing a constant flux of chloride ions. In order to calculate the diffusion coefficient of chloride ions for concrete under test, the flux $J$ is calculated with the constant slope of a regression line (Eq. (3)):

$J=\frac{V}{A} \frac{\Delta C_{\mathrm{cl}^{-}}}{t}$

where $V$ is the volume of solution in the anode compartment $\left(\mathrm{m}^{3}\right), A$ is the cross-sectional area of concrete $\left(\mathrm{m}^{2}\right), \Delta C_{\mathrm{cl}}^{-}$is the increase of concentration of chloride in the anode $\left(\mathrm{mol} / \mathrm{m}^{3}\right)$, and $t$ is the elapsed time (s), giving $\Delta C_{\mathrm{cl}}^{-} / t$ as the slope (See Fig. 4). The time to penetrate through the specimen is called lag time ( $\left.T_{\text {lag }}\right)$, which is the intersection point of the line with the $X$-axis. $T_{\text {lag }}$ depends on the porosity of concrete and chloride binding [16]. The results obtained in the present study of cracked and uncracked concretes are shown in Fig. 5. It is apparent that for cracks under $80 \mu \mathrm{m}$ the results show a transition period and a steady-state period characterised by a constant rate of chloride increase with time. The transition period was dependent on the crack width and on the concrete mixes. A higher crack width produced a shorter transition period and an increase in the slope. These slopes were used to calculate the diffusion coefficient of chloride ions using Eqs. (2) and (3). Fig. 6 presents the variation of lag time versus crack width. The results show that for uncracked concrete $T_{\text {lag }}$ of HPCSF is higher than for OC and HPC. A higher $T_{\text {lag }}$ may result from a lower porosity. This is an effect of the material. However, for cracked specimen it appears 


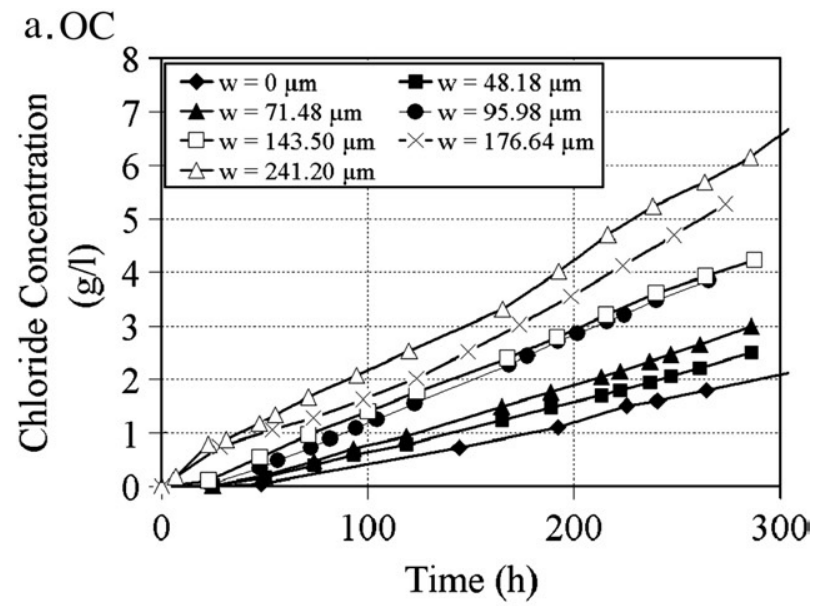

b.HPC
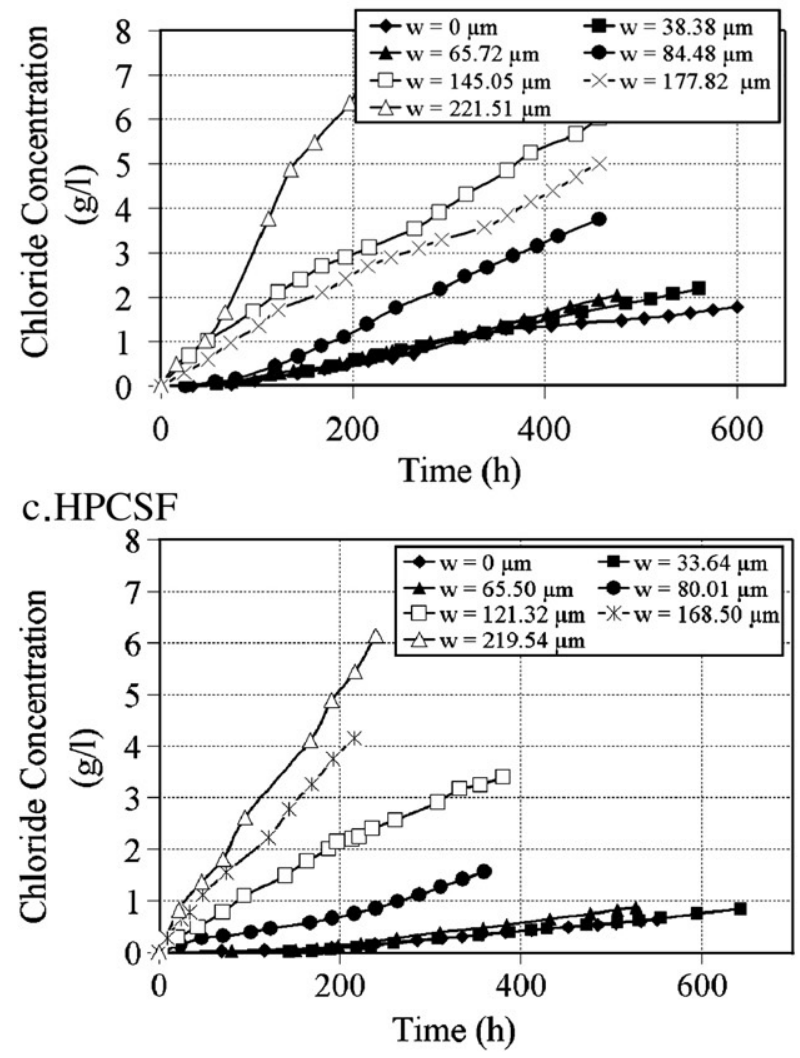

Fig. 5. Evolution cumulative increase of chloride concentration in downstream cell.

that $T_{\text {lag }}$ decreased with increasing crack width and was close to zero for crack widths above $80 \mu \mathrm{m}$.

\subsection{Effect of material and cracking on diffusion coefficient}

The effect of the water to cement ratio and the addition of silica fume on chloride diffusion coefficient was significant in this study (Fig. 7). For uncracked concrete the chloride diffusion coefficient increased with the increase of the porosity: chloride diffusion coefficient of OC was 2.37 that of HPC, and HPC was about 3 times that of HPCSF (Table 2). The addition of silica fume produced concrete with a higher compressive strength and

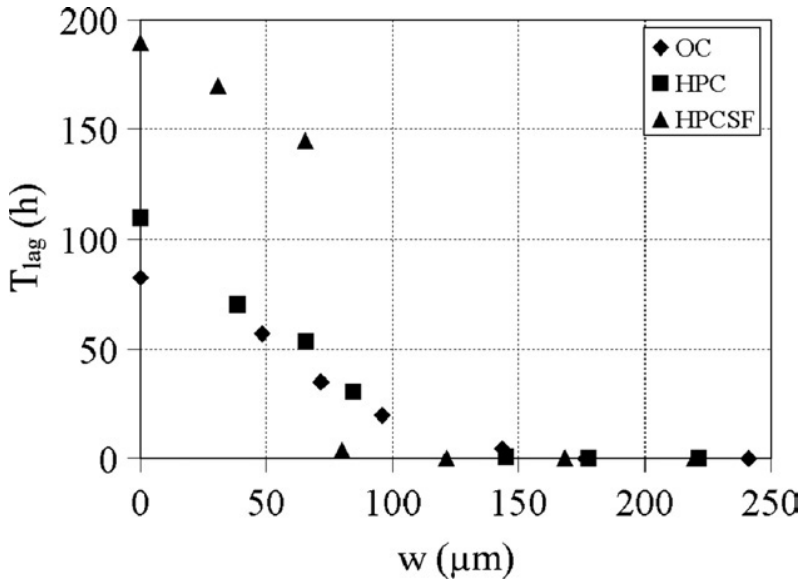

Fig. 6. Effect of crack width and material on time lag.

a lower porosity. This induced a better chloride resistance as shown by Sugiyama et al [18].

The chloride diffusion coefficient $D_{\mathrm{e}}$ of cracked samples was increasing with the increasing crack width. The results indicate that the OC, HPC and HPCSF concretes present the same trends. For crack widths $<80 \mu \mathrm{m}$, the diffusion coefficient increased moderately compared with that corresponding to uncracked concrete, whereas for crack widths $>80 \mu \mathrm{m}$, the diffusion coefficient increased rapidly. The relative increase $D / D_{0}$ will be examined in the following section to compare concretes.

\subsection{Relative increase in chloride diffusion}

The variation of the ratio $D / D_{0}$ with the average crack width is illustrated in Fig. 8. $D$ is the diffusion coefficient in cracked specimen and $D_{0}$ is the diffusion coefficient in uncracked specimen. $D / D_{0}$ of OC was smaller than $D / D_{0}$ of other concretes: there was a flow perpendicular to the crack which was not negligible. This was probably due to the higher porosity and crack tortuousity of OC. Therefore, chloride ion penetration through the crack to the inside of the concrete was considered to occur more easily in OC concrete compared with HPC and HPCFS. This essentially means that the effect of cracking on $D /$ $D_{0}$ is more important for dense materials with a low diffusion coefficient for the uncracked material.

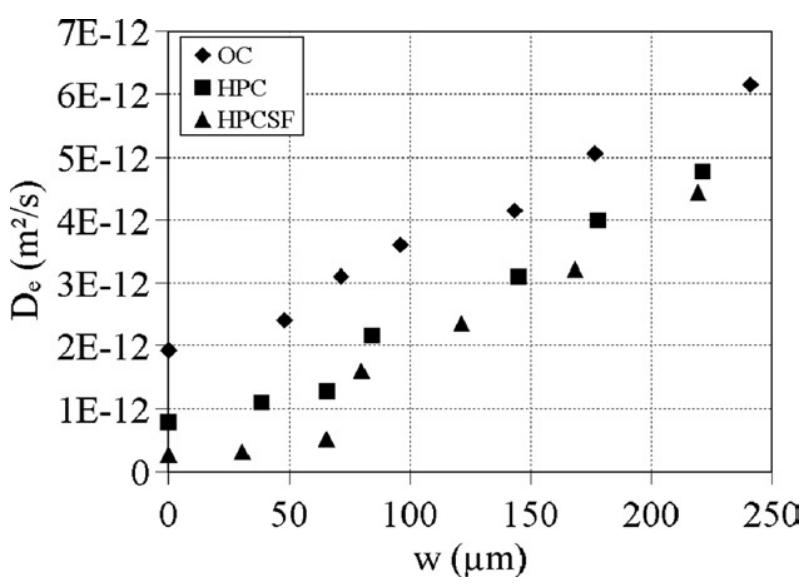

Fig. 7. Effect of crack width and material on steady-state chloride diffusion. 


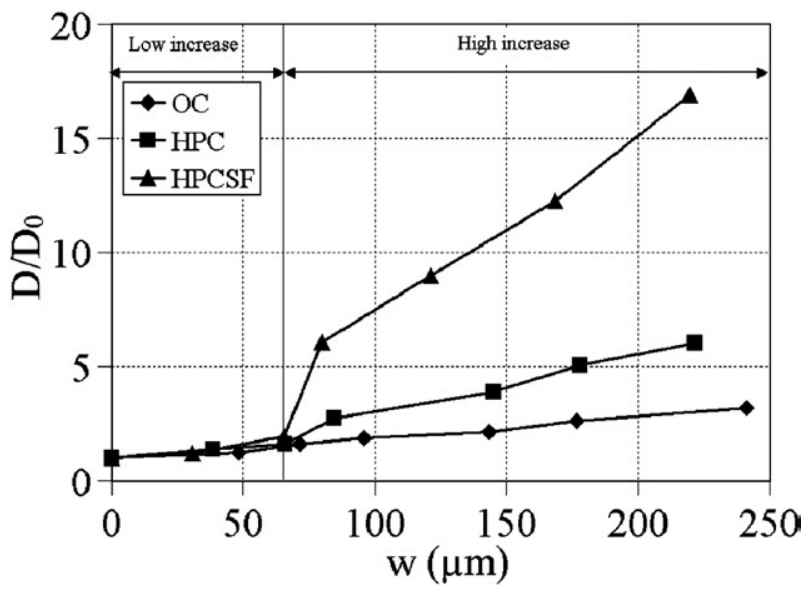

Fig. 8. The variation of the effective ratio $D / D_{0}$ versus the average crack width.

\subsection{Partition of chloride diffusion flow}

The chloride diffusion of these cracked discs was measured perpendicularly to plane faces. Transport properties in other direction have been neglected [10]. To investigate the effect of crack width on chloride penetration, the crack was presumed to propagate across the sample and was delimited by parallel planes perpendicular to the disc faces.

The total chloride diffusion flux of cracked concrete $J_{\mathrm{t}}$ (Eq. (4)) can be divided into two flows [6,7], as shown in Eq. (5) and Fig. 9:

- the flux in uncracked specimen $J_{0}$ described by Eq. (6)

- the flux in the crack $J_{\text {cr }}$ described by Eq. (7)

$$
\begin{aligned}
& J_{\mathrm{t}}=\frac{z F C \Delta E}{R T L} D \\
& \left(A+A_{\mathrm{cr}}\right) J_{\mathrm{t}}=A J_{0}+A_{\mathrm{cr}} J_{\mathrm{cr}}
\end{aligned}
$$

Where $A_{\text {cr }}$ is the crack area and $D_{\text {cr }}$ is the diffusion coefficient through the crack.

$$
\begin{aligned}
& J_{0}=\frac{z F C \Delta E}{R T L} D_{0} \\
& J_{\text {cr }}=\frac{z F C \Delta F}{R T L} D_{\text {cr }}
\end{aligned}
$$

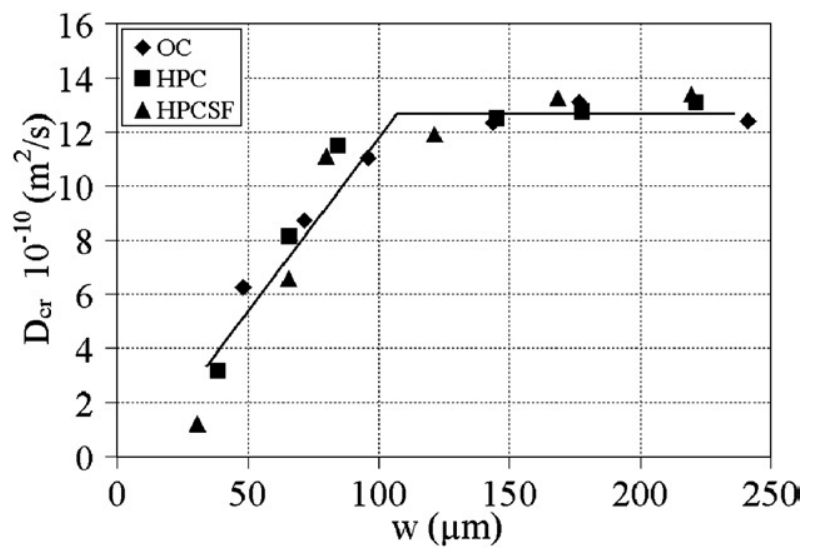

Fig. 10. Effect of crack width on diffusion coefficient through the crack.

By replacing Eqs. (5)-(7) in Eq. (4), one finds Eq. (8):

$D_{\text {cr }}=\frac{A\left(D-D_{0}\right)+A_{\mathrm{cr}} D}{A_{\mathrm{cr}}}$

Fig. 10 shows the relationship between the crack width and the diffusion coefficient of chloride ions through the crack determined by Eq. (8). $D_{\text {cr }}$ was increasing linearly with the increasing of crack width from 30 to $80 \mu \mathrm{m}$ and was almost constant when the crack width was approximately $80 \mu \mathrm{m}$ or more Eq. (9). This result indicates that $D_{\text {cr }}$ is independent of material effects, even if the tortuosity and roughness are different [10].

$$
\begin{cases}D_{\mathrm{cr}}\left(\mathrm{m}^{2} / \mathrm{s}\right)=2 \times 10^{-11} w-4 \times 10^{-10} & 30 \mu \mathrm{m} \leq w \leq 80 \mu \mathrm{m} \\ D_{\mathrm{cr}}\left(\mathrm{m}^{2} / \mathrm{s}\right) \approx 14 \times 10^{-10} & w \geq 80 \mu \mathrm{m}\end{cases}
$$

The variations of $D_{\mathrm{cr}}$ and time lag $T_{\text {lag }}$ are also shown in Fig. 11. $T_{\text {lag }}$ reduced with increasing $D_{\text {cr }}$ as can be seen for the most cracked specimen where the $T_{\text {lag }}$ tends towards to zero, the diffusion coefficient through the crack $D_{\text {cr }}$ was almost constant and the value obtained was the diffusion coefficient of chloride in free solution which is about $10^{-9} \mathrm{~m}^{2} / \mathrm{s}$.

\section{Conclusions}

The main conclusions of the present study are:

- Cracks traversing disc specimens can be obtained using a splitting tensile test.

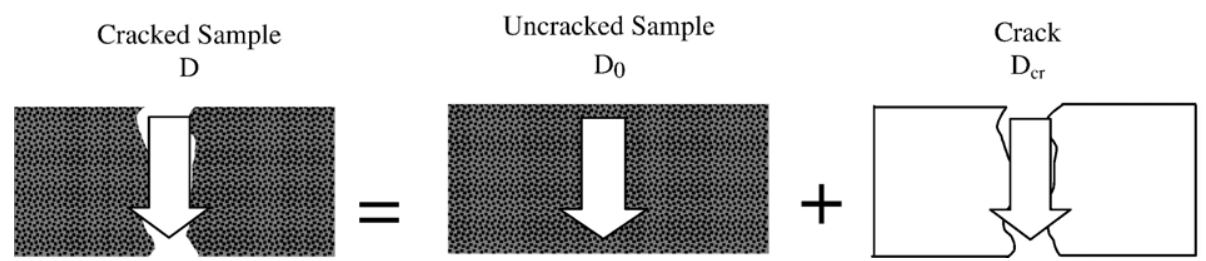

Fig. 9. Partition hypothesis of chloride diffusion through cracked discs. 


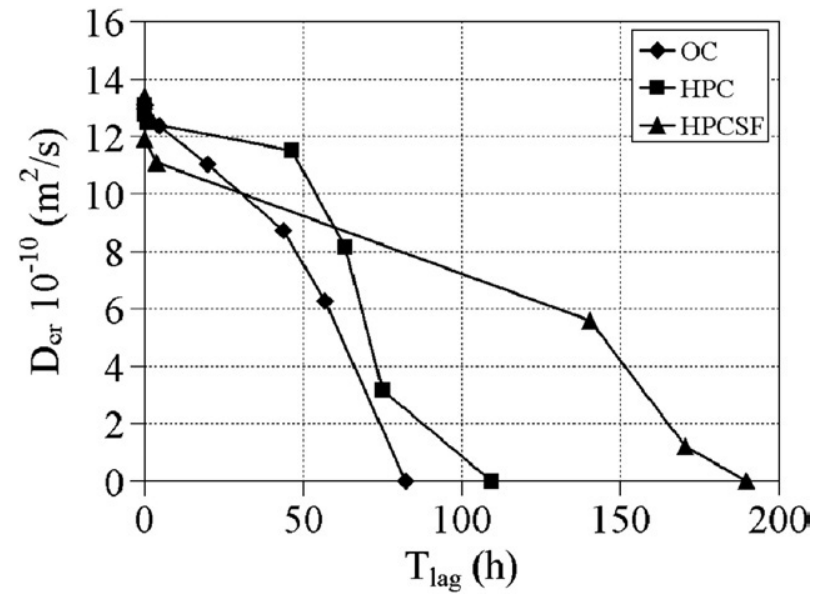

Fig. 11. Relationship between time lag and diffusion coefficient through the crack.

- For the entire range of crack widths, for the same COD under load, the crack width of OC was higher than for the two HPC mixes. This might be explained by a higher tortuosity of the cracks in OC, and thus a less elastic response.

- For uncracked concrete the chloride diffusion coefficient of OC was higher by a factor 2.44 compared to HPC, and HPC higher by a factor 3 compared to HPCSF. The result showed that time required before steady state was established for HPCSF is higher than the other concretes.

- The chloride diffusion coefficient $D_{\mathrm{e}}$ of cracked samples increases with the increasing crack width, the variation of $D_{\mathrm{e}}$ with crack width presents similar trends for all the three concretes investigated. The time to penetrate through the specimen is reduced which is very important to evaluate the initiation of corrosion.

- The ratio of $D$ for cracked over uncracked specimens is lower for OC than for HPC, therefore chloride ion penetration through the crack to inside the concrete is considered to occur more easily in OC than in HPC and HPCSF. This is mainly caused by the higher $D$ for uncracked OC which is related to its more porous and permeable microstructure.

- The diffusion coefficient through the crack $D_{\text {cr }}$ can be evaluated using a partition of chloride diffusion fluxes between uncracked concrete and crack volume. $D_{\mathrm{cr}}$ increases with the increasing of crack width and was almost constant when the crack width was approximately $80 \mu \mathrm{m}$ or more. This result indicates that $D_{\mathrm{cr}}$ is independent of material effect.

- The diffusion coefficient through the crack $D_{\mathrm{cr}}$ is increasing with the decrease in $T_{\text {lag }}$. For $T_{\text {lag }}$ close to $0, D_{\text {cr }}$ was almost constant and the value obtained is the diffusion coefficient for chloride ions in free solution.

\section{Acknowledgments}

The authors would like to acknowledge the financial support of "Laboratoire Central des Ponts et Chaussées (LCPC) France" and also the support of the European Union in the frame of the EU program Interreg III B - Atlantic Coast. This EU project MEDACHS deals with the maintenance and reliability of structures exposed to marine environment (Atlantic coast).

\section{References}

[1] T. Sugiyama, Determination of chloride diffusion coefficient and gas permeability of concrete and their relationship, Cem. Concr. Res. 26 (5) (1996) 781-790.

[2] M. Saito, Chloride permeability of concrete under static and repeated loading, Cem. Concr. Res. 25 (4) (1995) 803-808.

[3] C. Lim, Microcracking and chlorid permeability of concrete under uniaxial compression, Cem. Concr. Com. 22 (2000) 353-360.

[4] HR. Samaha, Influence of microcracking on the mass transport properties of concrete, ACI Mater. J. 89 (4) (1992) 416-424.

[5] S. Jacobsen, J. Marchand, L. Boisvert, Effect of cracking and healing on chloride transport in OPC concrete, Cem. Concr. Res. 26 (6) (1996) 869-881

[6] B. Gerard, J. Marchand, Part I: influence of continuous cracks on the steady-state regime, Cem. Concr. Res. 30 (1999) 37-43.

[7] C. Tognazzi, J.P. Ollivier, M. Carcasses, J.M. Torrenti, Couplage fissuration-dégradation chimique des matériaux cimentaires: premiers résultats sur les propriétés de transfert, in: Petit Pijauder Cabot Reynouard (Ed.), Ouvrage Géomatériaux et interactions-Modélisations Multi-Echelles, Hermes, France, 1998, pp. 69-84 (in French).

[8] C.M. Aldea, S.P. Shah, A. Karr, Effect of cracking on water and chloride permeability of concrete, J. Mater. Civ. Eng. (1999) 181-197.

[9] D. Witting, Rapid measurement of chloride permeability of concrete, Public Roads 45 (3) (1981) 101-112.

[10] GR. Olga, R. Doug Hooton, Influence of cracks on chloride ingress into concrete, ACI Mater. J. 100 (2) (2003) 120-126.

[11] NTBuild 443, Concrete, Hardened: Accelerated Chloride Penetration, Nordtest, Finland, 1995, pp. 1-5.

[12] R. Francois, A. Toumi, M. Ismail, A. Castel, T. Vidal, Effect of cracks on local diffusion of chloride and long-term corrosion behavior of reinforced concrete members, Proceedings of the International Workshop on Durability of Reinforced Concrete Under Combined Mechanical and Climatic Loads, Qingdao, China, 2005, pp. 113-122.

[13] Méthodes recommandées pour la mesure des grandeurs associées à la durabilité, Proceedings of Journées Techniques AFPC-AFREM, Durabilité des Bétons. France, Toulouse, 1998, pp. 121-124.

[14] K. Wang, Permeability study of cracked concrete, Cem. Concr. Res. 27 (3) (1997) 381-393.

[15] C. Andrade, Calculation of chloride diffusion coefficient in concrete from ionique diffusion measurements, Cem. Concr. Res. 23 (3) (1993) 724-742.

[16] O. Truc, A new way for determining the chloride diffusion coefficient in concrete from steady state diffusion test, Cem. Concr. Res. 30 (2000) 217-226.

[17] T. Luping, Chloride transport in concrete-Measurement and predictions, Doctoral thesis, Publication P-96:6, Dept. of Building Materials, Chalmers University of Technology, Gothenburg, Sweden, 1996.

[18] T. Sugiyama, Steady-state chloride migration test, Mag. Concr. Res. 53 (1) (2001). 